\title{
THE MICROBIAL INVASION OF GASTRO INTESTIANAL TRACT AND HABIT OF DRINKING WATER IMMEDIATELY AFTER MEALS
}

\author{
Kamal Prasad Parajuli, Durga Devi Chaulagain, Ganesh Singh and \\ Medhabi Shrestha
}

\begin{abstract}
The prime role of the hydrochloric acid secreted by the parietal cells of the stomach is to assist in digestion of food . The another important role of it is to assist in immunity. The presence and secretion of the hydrochloric acid is a part of innate immunity that fights against the pathogens that enter our body through oral route. However if a person drinks fluids while eating food, the hydrochloric acid whose $\mathrm{pH}$ is $2-3$, is greatly diluted and as a result the acid cannot effectively prevent the invasion of the GI tract by pathogens that are present in our food and water.This study reveals that those subjects who do not drink water while eating food but drink it after one hour of consumption of food are less likely to be infected with pathogens through GI tracts. Whereas those people who drink water while taking food are more prone to be infected by the pathogens.
\end{abstract}

Key words: Parietal cells, Churning action, hypochlorhydria, Lugol's iodine solution

\section{Introduction}

In developing countries like Nepal, parasitic infection of Gastro Intestinal Tract is rampant and the parasitic infection is one of the reasons for impairment of mental capabilities. It has been pointed out by various researches that the parasitic infection, particularly by the intestinal nematodes during childhood leads into poor mental IQs. $(1,2)$

Water is essential for life but provision of safe drinking water is still far from reach in poor people of developing countries. Unsafe drinking water is the cause of death of thousands of people in these countries. Such use of unsafe water for the preparation of meals and for drinking purposes is the root cause of various water borne diseases and faeco-oral transmitted diseases. Cholera, Dysentery, Typhoid fever, Viral diarrhea, Ascariasis, Amoebiasis, Giardiasis, etc are some of the diseases that are transmitted by consumption of contaminated water. $(3,4)$

The food that we eat may contain large number of pathogenic organisms including viruses, bacteria and parasites if it is prepared in dirty utensils, cooked measly and not covered properly after it has been cooked. Unhygienic preparation and consumption of such food is also one of the reasons for large number of parasitic infection in Nepal.

Hydrochloric acid in our body is secreted by parietal cells and poured into the stomach contents along with gastric juice. The main function of the hydrochloric acid is to aid in the digestion of food. Apart from this the hydrochloric acid also helps to attenuate any pathogens that enter into our GI system through food because most pathogens could not survive low $\mathrm{pH}$ of the hydrochloric acid. Once a person eats the food, the churning action of muscles of stomach inter-mixes the 
food completely with the acid so that pathogens that are present in the food cannot escape the deleterious action of the acid. However drinking of water during consumption of meals results into dilution of the acid, and as a result the pathogens escape unhurt and start showing their pathogenic effects once they reach small intestines. So drinking water while eating weakens our primary defense against the invading pathogens and thus we expose our self to harmful effects of microbial infections of the GI system. However if we drink water one hour after consumption of food we are safe from such types of infection. The aim of the study is to find out whether drinking of water at an appropriate time really decreases the burden of the microbial infection of GI system.

\section{Methods and Materials}

The study was conducted in the Department of Microbiology, at Nobel Medical College and Teaching Hospital, Biratnagar, Nepal. The questionnaires were prepared, after some basic information about the study the written consent was taken from the patients or from visitors who came to Microbiology lab to submit the stool samples and were enrolled in the study. All together 500 stool samples of both outdoor patients and indoor patients who had come to Nobel Medical College to seek treatment in between $15 / 8 / 2011$ to $25 / 10 / 2011$ were included in the study. The patients were given wide mouthed, clean and dry container and samples were processed within 30 minutes of collection of the stool samples.

Microscopic Examination of stool samples done according to standard protocol (5)

Preparation of saline solution and Lugol's Iodine solution- prepared as according to the Standard Protocol (6)

Any abnormal findings like ova and larva of Helminthes, and cysts and trophozoites of
Protozoan, pus cells, red blood cells, yeast cells, undigested food particles, etc were noted down. Presences of mucus, frank blood, consistency, etc were also noted macroscopically.

\section{Results}

Figure1 Sample frequency based on analysis $(\mathrm{N}=500)$

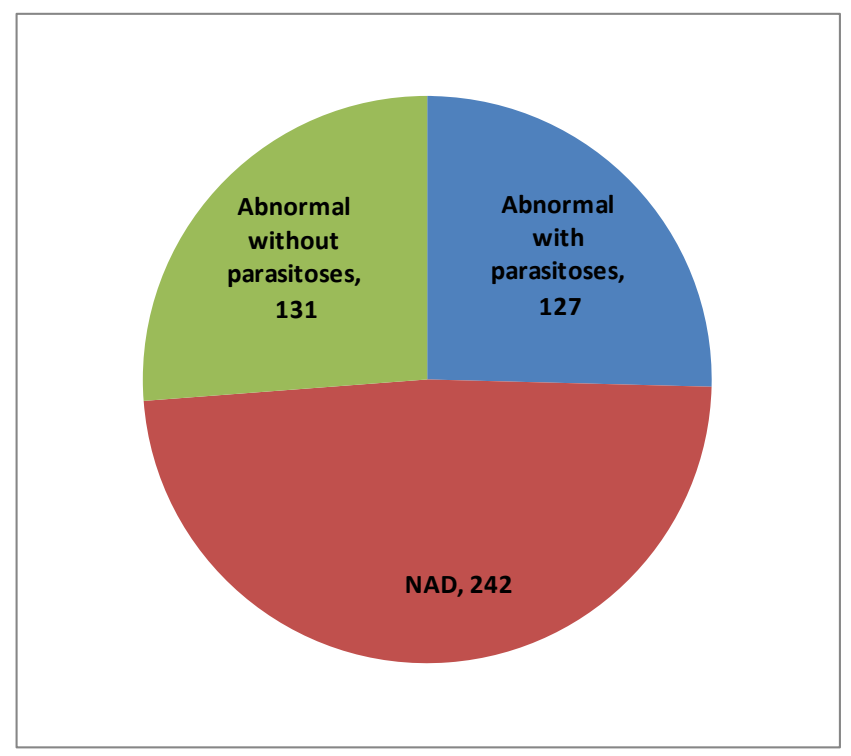

Out of 500 stool Fig. 1 shows samples analyzed 127 samples were found to have some sort of intestinal parasites ie Endameba histolyt- ica, Giardia lamblia Hookworm, Ascaris lumbricoides, Hymenolepis nana or Strongyloides stercoralis. Though parasites like Trichuris trichiura, Enterobius vermicularis, Taenia species etc are frequently observed during routine examination, they were not encountered during the study. 131 samples were abnormal by having pus cells, red blood cells, yeast cells etc but they did not have presence of any parasites. And finally 242 samples were completely free from any parasites or any other form of abnormalities. Identified with their frequencies according to habit of 
drinking water while examining stool samples. The frequency of parasites in infected persons who drank water before meals were less and similar was the result in those who drank water after meals. But most of the patients who harbored the parasites were the ones who drank water while taking foods.

Figure2: Frequency of parasites isolated according to habit of drinking water

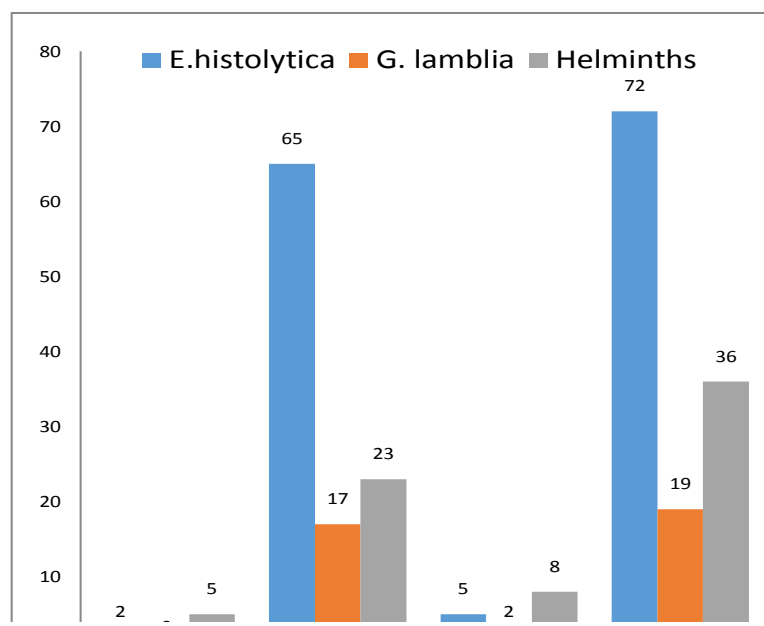

Figure 3 Habit of drinking water among the abnormal samples without parasitoses $(n=131)$

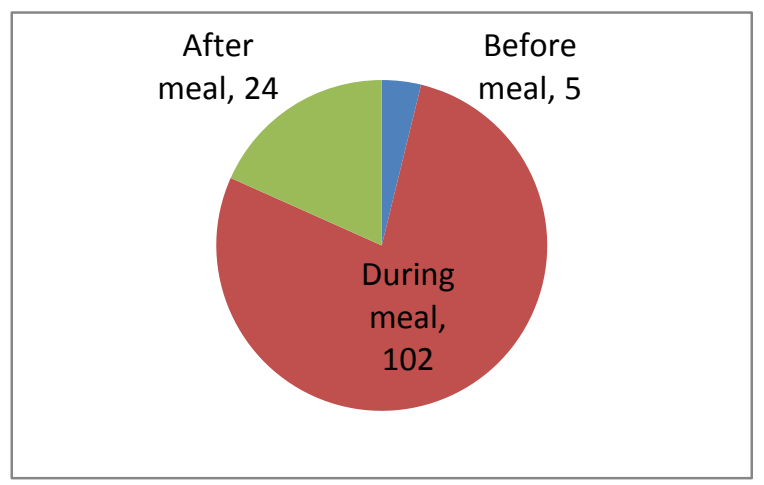

The figure shows the habit of drinking water among the abnormal samples without parasitosis but had some sort of abnormal findings in the stool examined .Out of 131 subjects, 5 and 24 drank water before and after meals respectively and still they had some abnormal findings in the stool samples. 102 subjects said they took water while eating foods.

\section{Discussion}

From the above study it has been found that people who drank water during the meals are more vulnerable to the microbial infections. This is because when water is taken along with food it is obvious that the hydrochloric acid secreted by the parietal cells get diluted, as a result its potency will not be as strong as when it is undiluted (7). So because of that reason the parasitic ova and cysts that enter our GIT cannot be destroyed by the acid. We all know that presence of hydrochloric acid in the stomach bars many pathogenic organisms entering into the GI system (8).Similar to what the author has found, this article points out that the acid prevents the harmful microorganisms entering into the GI system and the role of the acid is minimized once people start gulping water and food together. Facts like " $10^{6}$ Vibrio cholerae administered to normochlohydric volunteers without food and buffer did not produce infection while the same dose given along with food and buffer caused the clinical cholera,"(9) suggests that presence of hydrochloric acid in stomach prevents infections.

In certain helminthes infections like Hookworm and Strongyloides stercoralis infections, though the mode of transmission is not the faeco-oral route, but still they come to stomach. The larval form of these parasites remains in the stomach for certain period of time and along with the food they migrate to the small intestines, their final destination. The secretion of Hydrochloric acid is high in the gastric phase but again if it is diluted, these parasites pass unhurt from the stomach to the intestines and cause infections. 
Similar to other studies conducted by various authors in different part of Nepal $(10,11)$, Amoebiasis is the highest among the subjects and second to this is giardiasis. Both these disease are mostly transmitted by the faecooral route mainly by consumption of contaminated food and water. If people instead of drinking water while eating food start taking water after some time of taking of food these parasitic infections can be prevented.

\section{Conclusion}

The study reveals that appropriate time for drinking water is necessary to avoid various intestinal ailments due to microorganisms and the best time to do so is not during or immediately after the intake of foods but after some time of the intake of foods.

\section{Acknowledgement}

The study was conducted in the Microbiology lab of Nobel Medical College and Teaching Hospital, so the author is indebted to all the patients who took part in the study. It is needless to say that without the help of $\mathrm{Mr}$ Binod Yadav, Miss Srijana Rai, Miss Kabita Chaudhary and Mr Birendra Sardar, who gave their valuable time in processing the stool samples in the department, the study would not have been possible. The author would also like to thank his daughter, Miss Neeharika Parajuli and son Aakash Krishna Parajuli, for their help in computer typing and settings.

\section{References}

1. Correlation between intestinal parasitosis, physical growth and pschymotor development among infants and children from rural Nicaragua, -American Journal of Tropical Medicine and Hygiene ,58:470-475

2. The contribution of Ascaris lumbricoides to malnutrition to children, Parasitology 81, 221

3. Epidemiology of Amoebiasis, Pasitol,6,1

4. Bull. N.Y. Amoebiasis as world problem, Acad.Med. 47,438

5. L. S Garcia. Diagnostic Medical Parasitology by $4^{\text {th Edition }}$ Page 741-746.

6. L.S. Garcia. Diagnostic Medical Parasitology by $4^{\text {th }}$ Edition, page 744.

7. Diseases associated with low HCL, Gallbladder attack.com

8. Micheal Mc Evoy. Your Digestive Fire: The Vital Role of Stomach Acid

9. R Ananthanarayan and CK Panikar Text book of Microbiology, $5^{\text {th }}$ edition ,page 286.

10. Small scale survey on status of intestinal parasites infection in rural villages in Nepal, Korean Journal of Parasites, 38(4) :275-277

11. Shakya B. Intestinal parasites, Journal of Institute of Medicine, December 2009, 31:3 